\title{
O JUDICIÁRIO E A DEMARCAÇÃO DE TERRAS INDÍGENAS: O CASO DE PERNAMBUCO
}

THE JUDICIARY AND THE DEMARCATION OF INDIGENOUS LANDS: THE CASE OF PERNAMBUCO

Fernando Joaquim Ferreira Maia ${ }^{1}$

Gilberto Romeiro de Souza Júnior²

\begin{abstract}
Resumo: Neste artigo trata-se dos conflitos envolvendo terras indígenas em Pernambuco pelo Judiciário. A análise foi feita a partir das decisões em Pernambuco e que tratam dos processos de conflitos de terras indígenas. No estudo empregam-se as noções do direito do acesso à terra e o posicionamento dos juízes na resolução dos conflitos envolvendo terras indígenas. Analisa-se a atuação da jurisdição diante das questões de terras indígenas, bem como investigam-se os possíveis cenários desses conflitos no Estado. Utilizaram-se como instrumentos de pesquisa livros e artigos de Direito e Sociologia sobre conflitos ambientais sobre apropriação de terras, e as decisões judiciais acerca dos conflitos pelo direito à terra nas comunidades indígenas. Defende-se que o Judiciário age de forma incoerente ao aplicar a norma material ambiental nos conflitos envolvendo as terras indígenas. Portanto, os povos indígenas não encontram no Judiciário um campo favorável para defesa dos seus direitos relativos à terra.
\end{abstract}

Palavras-chave: Análise judicial. Direito à terra. Indígenas. Conflito.

\begin{abstract}
The article deals with the conflicts involving indigenous lands in Pernambuco by the Judiciary. The analysis was made from the decisions in Pernambuco and dealing with conflict processes of indigenous lands. The study employs the concepts of the right of access to land and the placement of judges in resolving conflicts involving indigenous lands. The performance of jurisdiction on matters of indigenous lands is analyzed, and the possible scenarios of these conflicts in the State are investigated. As instrument of research, books and articles of environmental law and rural sociology, on environmental conflicts over land ownership, and the judgments on the conflicts for the right to land in the indigenous communities were used. It argues that the Judiciary acts inconsistent in applying the standard environmental material in conflicts involving indigenous lands. Therefore, indigenous peoples do not find in the Judiciary a favorable field for defence of their rights to the land.
\end{abstract} Keywords: Judicial review. Land rights. Indigenous. Conflict.

\footnotetext{
1 Doutor e Mestre em Direito pela Universidade Federal de Pernambuco; Professor no Programa de Pós-Graduação em Ciências Jurídicas da Universidade Federal da Paraíba; Departamento de Ciências Sociais, Rua Dom Manoel de Medeiros, Dois Irmãos, 52171-900, Recife, Pernambuco, Brasil; fernandojoaquimmaia@gmail.com

2 Graduando em Ciências Sociais pela Universidade Federal de Pernambuco; Membro do Núcleo Multidisciplinar de Pesquisa em Direito e Sociedade; gilbertorsjr@gmail.com
} 


\section{Introdução}

Esta pesquisa é fruto do plano de trabalho aprovado para o Programa de Iniciação Científica desenvolvido na Universidade Federal Rural de Pernambuco com o apoio da CAPES e parte das discussões do projeto de pesquisa Retórica, meio ambiente e poder judiciário: as ideias sobre o meio ambiente nas decisões judiciais no Estado de Pernambuco.

As questões que envolvem as terras indígenas são muito complexas e conflituosas, sobretudo em razão das interpretações fora dos limites fixados pelo art. 231 da Constituição Federal de 1988 (BORGES, 2014). Por isso, não se pode recusar o importante papel atribuído ao Poder Judiciário no que concerne à estipulação de alguns marcos teóricos em relação às terras indígenas, considerando o novo paradigma instaurado pela Constituição de 1988. Ainda persiste certa incompreensão a respeito da natureza do território indígena e das repercussões jurídicas correlatas. O próprio processo em que a discussão dessa temática é desenvolvida revela, por si, essa marca em diferentes perspectivas.

Os conflitos ambientais envolvendo terras indígenas, historicamente, foram marcados por interesses antagônicos entre os indígenas e a burguesia portuguesa. Os desfechos mostraram-se, ao final, amplamente desfavoráveis aos povos indígenas, e não apenas em relação à perda de terra. Daí a importância da presente pesquisa: esclarecer as realidades e distorções que envolvem as questões dos conflitos sobre terras indígenas no Poder Judiciário em Pernambuco.

Em relação à metodologia, parte-se de uma perspectiva materialista dialética e multidisciplinar com o aporte, sobretudo, do Direito e da Sociologia. Como instrumentos de pesquisa foram utilizadas as decisões judiciais acerca dos conflitos de terras indígenas em Pernambuco e livros e artigos diretamente ligados à temática em questão. Como situações-problema têm-se os seguintes questionamentos: qual a logicidade de tratamento dos conflitos de terra adotada pelo Sistema de Justiça que pode ser inferida das decisões judiciais em Pernambuco? Quais os elementos ideológicos que são extraídos dos discursos e práticas judiciais?

O próprio Estado percebe que deve estimular seus órgãos jurisdicionais a agir de ofício nas questões ambientais, mais especificamente naquelas que dizem respeito às situações conflituosas de terras que atingem os povos indígenas. Observa-se que é justamente no litígio, além do poder político, que se revela a bidimensionalidade teleológica da sentença judicial, por meio do qual o juiz atua num primeiro momento para proteger/reproduzir as relações jurídicas materiais e, num segundo momento, para proteger/reproduzir as próprias relações sociais.

\section{A intervenção do movimento indígena na América Latina}

A formulação e a implementação de políticas públicas que envolvem os povos indígenas devem ser consideradas pelos Estados não apenas pelo viés étnico, mas principalmente pelo político. Por outro lado, no mundo contemporâneo, o direito dos povos indígenas não está restrito apenas 
à política interna de cada país, mas está se transformando em normas de ordem internacional que cada país deve aplicar em escala local (CONSELHO ECONÔMICO E SOCIAL DAS NAÇÕES UNIDAS, 2006).

O desenvolvimento do Direito em âmbito internacional ocorreu de modo gradual ao longo do século XX, em direção à superação do sentimento individualista dos Direitos Humanos, apesar da Declaração Universal de 1948 e do caráter integracionista das políticas setoriais e dos acordos governamentais. Na América Latina, as ações formais relativas à legislação indígena foram direcionadas sob o viés da integração das populações indígenas e datam do $1^{\circ}$ Congresso Indigenista Interamericano de Pátzcuaro, no México, em 1940, com o objetivo de articular a legislação indigenista e sistematizar os princípios jurídicos e constitucionais dos países-membros. Em 1957, a Organização Internacional do Trabalho (OIT), mediante o Convênio 107 sobre Populações Indígenas e Tribais, adotou diversas cláusulas para os países signatários com o objetivo de orientar as ações do Governo em matéria indígena. Nesse contexto, apesar do avanço nas questões de direito à terra e dos aspectos culturais e étnicos, tal Convênio coube aos governos com o objetivo de desenvolver ações e programas para integração progressiva das comunidades indígenas no País. Outro importante avanço destacado nesse Convênio está no reconhecimento do direito aos recursos naturais e às terras tradicionalmente ocupadas pelos indígenas, considerando que, nos casos em que pertencer ao Estado a propriedade dos recursos existentes nas terras, o uso deverá estar pautado por consultas aos povos interessados, reservando a eles a indenização por efeitos danosos que possam advir desse uso. Parte fundamental desse direito central é a garantia das terras tradicionais pelos governos. Atenção especial deverá ser dada aos valores espirituais dos povos autóctones, reconhecendo os direitos de propriedade e posse das terras tradicionalmente ocupadas por esses povos.

É válido ressaltar a participação de organizações de apoio aos índios para o surgimento da questão indigenista no Brasil em meados da década de 1970. Entre elas destacam-se: as comissões pró-índio (CPIs), as associações nacionais de apoio ao índio (ANAIs), o Conselho Indigenista Missionário (CIMI), o Centro de Trabalho Indigenista (CTI), a Operação Amazônia Nativa (Opan), o Centro Ecumênico de Documentação e Informação (CEDI) e o Núcleo de Direitos Indígenas (NDI). Criadas por intelectuais envolvidos com a questão indígena, essas organizações passaram a desenvolver importantes trabalhos, como o questionamento fundamentado às políticas oficiais, a interlocução entre índios e Funai, bem como a formulação de alternativas concretas para o indigenismo brasileiro (SANTILLI, 1991; SOUZA LIMA; BARROSO HOFFMANN, 2002). De modo geral, os indígenas na América Latina assumiram sua forma de organização social, econômica e política em relação ao Estado e à sociedade ao longo das últimas quatro décadas do século XX, conseguindo em alguns países, como o Brasil, até a década de 1990, que suas ações ganhassem impacto nacional. Nesse contexto, a temática indígena sofreu mudanças significativas, entre as quais a consolidação dos movimentos indígenas como atores políticos, o que propiciou maiores reivindicações para a 
efetivação dos seus direitos pela posse e propriedade de terras tradicionais e mudanças significativas nas políticas públicas dos países latino-americanos (CEPAL, 2006b).

Nos parágrafos que seguem são retratadas as ideias centrais sobre a questão indígena no pensamento de José Carlos Mariátegui.

A produção intelectual que toma como referencial teórico o "indigenismo" é tratada de maneira contraditória nos posicionamentos dos intelectuais dos países-membros da América Latina. De fato, há uma diferença entre o indianismo do século XIX e o indigenismo do século XX. Essa postura diferente é alimentada pelo poder de atração dos levantes indígenas que levavam quase meio século. A esse respeito, Mariátegui (2010, p. 317) diz:

[...] finalmente, não se pode equiparar a atual corrente indigenista com a velha corrente colonialista [refere-se ao indianismo]. O colonialismo, reflexo do sentimento de casta feudal, se entretinha com a idealização nostálgica do passado. $O$ indigenismo, em troca, tem raízes vivas no presente. Extrai sua inspiração no protesto de milhões de homens.

Essa tese, mais tarde, foi corroborada por Quijano (2017), pois, obviamente, não se podia comparar a servidão feudal existente na Europa com a praticada com as populações originárias na América Latina:

A servidão dos índios na América não pode ser, por outro lado, simplesmente equiparada à servidão no feudalismo europeu, já que não incluía a suposta proteção de nenhum senhor feudal, nem sempre, nem necessariamente, a posse de uma porção de terra para cultivar, no lugar de salário. Sobretudo antes da Independência, a reprodução da força de trabalho do servo índio se fazia nas comunidades. Mas mesmo mais de cem anos depois da Independência, uma parte ampla da servidão indígena era obrigada a reproduzir sua força de trabalho por sua própria conta. E a outra forma de trabalho não-assalariado, o não pago simplesmente, o trabalho escravo, foi restrita, exclusivamente, à população trazida da futura África e chamada de negra. (QUIJANO, 2017).

O indigenismo como o pensava e vivia Mariátegui não era uma intenção voltada ao passado pré-colombiano. Seu posicionamento estava voltado para a maneira como ele entendia a luta socialista na América Latina. E aqui começa a revelar-se a natureza de sua contribuição original. Vale ressaltar como seu pensamento acentuava resolutamente a necessidade de se pensar quais eram os instrumentos de trabalho fundamentais dos quais o proletariado havia sido expropriado: a terra.

O problema indígena se identifica com o problema da terra. A ignorância, o atraso e a miséria dos indígenas não são, repetimos, senão a consequência de sua servidão. O latifúndio feudal mantém a exploração e a dominação absoluta das massas indígenas pela classe. A luta dos índios contra os "gamonais" baseou-se invariavelmente na defesa de suas terras contra a absorção e o despojo. Existe, portanto, uma instintiva e profunda reivindicação indígena: a reivindicação pela terra. Dar um caráter organizado, sistemático, definitivo, a esta reivindicação, é a tarefa que temos o dever de realizar ativamente. (MARIÁTEGUI, 1991). 
Posteriormente, isso é apontado por Quijano (2005) como um traço da distribuição racista do trabalho no interior do capitalismo moderno. Apesar de, inicialmente, os índios não terem sido trabalhadores livres e assalariados, com o tempo a distribuição racista de novas identidades sociais foi combinada com uma distribuição racista do trabalho e das formas de exploração do capitalismo. Caberia aos brancos os melhores postos de trabalho e os melhores salários, e aos povos originários da América, participar da divisão do trabalho da sociedade capitalista na condição de proletários e camponeses para empregar a sua força na reprodução interna de capital e sua exportação para o centro do capitalismo mundial.

O pensamento de Mariátegui (1991) retrata a questão indígena e o socialismo a partir do olhar do outro. O vínculo do proletariado do País com formas comunais o predispunha a um tipo de sociabilidade que somente o socialismo permitiria que vingasse no conjunto da vida nacional. Ao mesmo tempo, ele via no socialismo a única saída para os problemas enfrentados pelos indígenas, uma vez que recusava toda forma de retorno ao passado e também não deixava de vincular a questão da terra à pulsão capitalista pela propriedade privada.

\section{Povos indígenas: sujeitos de direitos e produtores de normas jurídicas próprias}

A Constituição de 1988 ampliou os direitos dos indígenas, positivando direitos relacionados às terras, com imposição à União do dever de proteção do indígena. Para Montanari Júnior (2009, p. 5), a Constituição de 1988, em relação às anteriores, tem uma abordagem diferente sobre a questão, pois estabelece a responsabilidade do Estado sobre a proteção do indígena:

[...] além de enfrentar o tema com destemor ainda não observado nas anteriores, estabeleceu uma nova fundamentação a ser repensada, como a desentranhamento do conceito civilista de propriedade, o direito congênito, dentre outros aspectos, colocando à margem a política assimilacionista, própria do sistema jurídico precedente, mas que permeia ainda a mente de muitos que pelejam nesta seara. $O$ Poder Público passou a ser o responsável pela proteção integral dos direitos dos povos indígenas como visto nos artigos 20, XI; 22 XIV; 49,IX; 109, V; 176 e 67 do Ato das Disposições Constitucionais Transitórias, mormente a União que passou a centralizar através da FUNAI - Fundação Nacional do Índio tal desiderato [...]

Quanto ao indigenato, a disposição no art. 231 da Constituição Federal reconhece direitos originários dos índios sobre as terras que tradicionalmente ocupam. Os direitos dos indígenas, pela Constituição, decorrem da ocupação tradicional pelos índios e permanência em suas terras. A questão da terra se transforma em um ponto central dos direitos dos índios, pois, para eles, a terra tem um valor de sobrevivência física e cultural. Não se amparará o direito dos índios se não lhes assegurar a posse permanente das terras por eles ocupadas.

Segundo Borges (2014, p. 79), as normas constitucionais vigentes vieram apenas consolidar o que o direito anterior já estabelecia, criando um alcance verdadeiramente profundo e abrangente. No entendimento do autor, quem cria as equivocadas interpretações a respeito dos conceitos 
dessa norma assim procede por razões que não a de proteger o indígena, mas de favorecer o conflito com os não índios, já que a Lei Maior é coerente, não dando margem de dúvida quanto às expressões "tradicionalmente ocupadas" e "habitadas permanentemente".

Segundo a Constituição (art. 231, $\mathbb{\int} 1^{\circ}$ ), são terras tradicionalmente ocupadas pelos índios: (1) as por eles habitadas em caráter permanente; (2) as utilizadas para suas atividades produtivas; (3) as imprescindíveis à preservação dos recursos ambientais necessários ao seu bem-estar; e (4) as necessárias a sua reprodução física e cultural, segundo seus usos, costumes e tradições (BRASIL, 1988). Nesse raciocínio, deve ser considerado o fator continuidade viva da posse dos indígenas, devidamente exteriorizada pela apreensão física e traduzida pela palavra "permanentemente", ou seja, aquilo que está provado por sinais evidentes que atestam o consenso histórico, como comumente acontece na modernidade (BORGES, 2014, p. 97).

Nesse entendimento, assenta Veiga Rios (2002, p. 65-66):

Um aspecto de fundamental importância para entender o alcance da proteção constitucional às populações indígenas se refere ao tempo. Assim, se é claro que as terras tradicionalmente ocupadas pelos índios se destinam à sua ocupação permanente, isso não significa apenas um pressuposto do passado para caracterizar a posse efetiva no presente. Trata-se, na verdade, de uma herança do passado, fruto de um direito originário e preexistente à ocupação ocidental, para a proteção efetiva do presente, mas que tem por principal objetivo a garantia do futuro, no sentido de que essas terras estão para sempre destinadas a ser hábitat permanente das populações indígenas.

É importante, ainda, destacar o que o professor Antunes (1988, p. 2) afirma quando se refere aos artigos da Constituição Federal de 1988 que tratam especificamente das terras indígenas:

A Constituição de 1988 não criou novas áreas indígenas. Ao contrário, limitou-se a reconhecer as já existentes. Tal reconhecimento, contudo, não se cingiu às terras indígenas já demarcadas. As áreas demarcadas, evidentemente, não necessitavam do reconhecimento constitucional, pois, ao nível da legislação infraconstitucional, já se encontravam afetadas aos povos indígenas. O que foi feito pela Constituição foi o reconhecimento de situações fáticas, isto é, a Lei Fundamental, independentemente de qualquer norma de menor hierarquia, fixou critérios capazes de possibilitar o reconhecimento jurídico das terras indígenas. Não se criou direito novo. A demarcação das terras tem única e exclusivamente a função de criar uma delimitação espacial da titularidade indígena e de opô-la a terceiros. A demarcação não é constitutiva. Aquilo que constitui o direito indígena sobre as suas terras é a própria presença indígena e a vinculação dos índios à terra, cujo reconhecimento foi efetuado pela Constituição Brasileira.

Dessa forma, para a caracterização da terra indígena a partir dos parâmetros do art. 231 da Constituição Federal de 1988, é válido considerar a simultaneidade dos pressupostos (originariedade, tradicionalidade e permanência), pois a ausência de apenas um interferirá em sua caracterização, bem como a negação de algum dos pressupostos implicará a desqualificação indígena da terra, não sendo considerado aqui o termo qualificação um ato formal, mas apenas conceitual. 


\section{A incoerência jurídica entre os parâmetros estabelecidos pela Constituição de 1988 e 0 Estatuto do Índio e a realidade vivenciada pelos indígenas em Pernambuco}

As terras ocupadas por comunidade indígena são protegidas pela Constituição Federal (arts. 20, inciso XI; 22, inciso XIV; 49, inciso XVI; 129, inciso V; 176, \$1; 231; 232; art. 67 (ADCT)). Também são protegidas pelo Estatuto do Índio (Lei n. 6.001) (BRASIL, 1973), tendo tratamento especial, mesmo diante de título aquisitivo de propriedade. São esses comandos normativos que criam a categoria de terra indígena.

Para Barbosa (2001), embora possam os índios, como qualquer outro indivíduo, adquirir a posse e a propriedade por todos os meios previstos pelo ordenamento brasileiro, tal aquisição de propriedade não se confunde com as terras constitucionalmente protegidas como terras indígenas.

Para alguns autores, como Falcão (1995), trata-se de violação ao direito de propriedade dos índios, pois as terras de domínio particular, sendo indígenas, estão sujeitas a regras de proteção e restrição previstas pela lei. Nesse entendimento, o autor reitera:

O índio, bem como a comunidade indígena, poderá ser senhor do domínio pleno da terra que haja adquirido por qualquer das formas de aquisição admitidas pelo Direito Civil pátrio, consoante a previsão legal contida no art. 32 da Lei n ${ }^{\circ} 6.001$, de 1973. Essa terra não estará incluída, evidentemente, entre as chamadas "terras indígenas" latu sensu, ou seja, aquelas de ocupação permanente a que se reporta a Constituição da República e, como tais, integrantes do patrimônio da União. Embora isto se constitua o óbvio, não é o que pareceu ao legislador que redacionou o Estatuto do Índio quando concebeu o art. 17, que arrolou-as erroneamente entre as chamadas terras indígenas. (FALCÃO, 1995).

Conforme essa perspectiva, nos casos envolvendo tais situações no Estado de Pernambuco, a Funai assume imediatamente a posição de administradora das terras cuja regularização os índios haviam conseguido. Nesses casos, prevalece a interpretação burocrática e autoritária, segundo a qual as terras indígenas pertencem ao patrimônio da União.

Em uma abordagem geral, no Estado de Pernambuco, existem 13 povos indígenas com uma população de aproximadamente 53 mil habitantes, que representam cerca de $2 \%$ da população rural do Estado (0,6\% da população total). Eles ocupam um território de, aproximadamente, 179.263 hectares (considerando os territórios em processo de identificação e homologação), localizados em 16 municípios, distribuídos em seis regiões do Estado de Pernambuco. Nessa perspectiva, 10 territórios indígenas no Estado já foram homologados juridicamente, são eles: Atikum (Carnaubeira da Penha e Floresta), Fulnio-ô (Águas Belas), Kambiwá (Ibimirim), Kapinawá (Ibimirim, Tupanatinga e Buíque), Pankaiuká (Jatobá), Pankararú e Pankararú entre Serras (Tacaratu, Petrolândia e Jatobá), Truká (Cabrobó), Tuxá (Inajá) e Xucurú (Pesqueira). Juntos abrangem uma área total de 118.263 hectares e abrigam $86 \%$ da população indígena do estado (FUNDAÇÃO NACIONAL DO ÍNDIO, 2010). 


\section{As distorções nos procedimentos demarcatórios de terras indígenas e 0 acirramento dos conflitos de terra}

Ao iniciar a abordagem relativa às questões de demarcação de terras indígenas, apresenta-se uma definição do termo Demarcação de Terras Indígenas, conforme o Dicionário de Direitos Humanos (GRABNER, 2009, p. 1):

Procedimento administrativo de iniciativa da União visando a identificação e delimitação das terras tradicionalmente ocupadas pelos índios, regulado pelo Decreto ${ }^{\circ} 1.775$ de 08 de janeiro de 1996, em obediência ao disposto no artigo 231 da Constituição Federal e artigo 67 do seu Ato das Disposições Constitucionais Transitórias. A demarcação administrativa das terras tradicionalmente ocupadas pelos índios é orientada pelo órgão federal de assistência ao índio, a FUNAI, comportando as seguintes fases: identificação e delimitação; aprovação e publicação, impugnação, decisão e demarcação propriamente dita, homologação e registro. Fundamenta-se em estudo antropológico de identificação elaborado por grupo técnico especializado coordenado por antropólogo, formado com o fim de apurar a natureza etno-histórica, sociológica, jurídica, cartográfica e ambiental das terras e pressupõe a participação do grupo indígena envolvido em todas as fases do procedimento.

Segundo Grabner (2009, p. 1), "a omissão da União nas questões de demarcação das terras tradicionalmente ocupadas pelos índios - seu espaço de vida e liberdade - constitui violação dos direitos humanos individuais e coletivos desses povos", o que, de certa forma, contribui para o acirramento dos conflitos de terras nas comunidades indígenas. Esse fato se incide pela não efetivação das políticas públicas endereçadas aos indígenas (arts. 210 e 215 da Constituição Federal) e também pela afronta aos tratados internacionais que conferem proteção à diversidade étnico-cultural, a exemplo da Convenção 169 da OIT. O autor reitera que "o direito à declaração judicial de um território como sendo indígena constitui mais um instrumento na realização dos direitos sociais e culturais dos índios e na conservação dos recursos naturais imprescindíveis ao bem-estar de índios e não índios."

As terras indígenas, no tratamento que lhes foi dado pelo novo Texto Constitucional, são concebidas como espaços indispensáveis ao exercício dos direitos identitários desses grupos étnicos. A tríade etnia-cultura-território é, em larga medida, indissociável. No entanto, a prática do Judiciário tende a equiparar ambos elementos (propriedade privada e território indígena), conferindo-lhes tratamento processual idêntico. Mediante a coleta de decisões judiciais relativas à problemática dos processos demarcatórios de terras indígenas, no Estado de Pernambuco a situação mais recorrente seria a propositura de ações possessórias em face dessas terras. Cita-se, como exemplo, o processo judicial de número 000027278.2013.4.05.8304, que tramita na Seção Judiciária de Pernambuco - $20^{a}$ Vara Federal -, que trata mais especificamente da mora na conclusão do Processo Administrativo de Demarcação e Delimitação das terras tradicionalmente ocupadas pelos índios Pankarás em Carnaubeira da Penha, Pernambuco. O fundamento do processo foi estabelecer o prazo de 60 dias a contar do trânsito em julgado da sentença para que o Relatório Circunstanciado de Identificação e Delimi- 
tação (RCID) das terras em questão seja devidamente concluído e analisado pelo presidente da Funai nos termos do Decreto n. 1775/96.

Para Borges (2008, p. 28), "a questão de terras indígenas é muito complexa e conflituosa, porque alguns intérpretes tendenciosos procuram dar uma interpretação fora dos limites e contornos que são fixados pela mens legis do art. 231 e seu $\int 1^{\circ}$ da Constituição Federal de 1988."

É válido ressaltar que o fato de a demarcação se constituir em um ato declaratório não quer dizer que retirará sua importância nem a necessidade de a União concluir tal processo. Em decorrência de desrespeitos aos direitos indígenas, tanto no que diz respeito à cultura quanto à posse sobre as terras tradicionalmente ocupadas, grande parte das terras indígenas possui a presença de não índios, que acabam se apropriando dessas terras ou as invadindo para a retirada de recursos naturais ou simplesmente para fixação de moradia. Nesse sentido, fica claro que os procedimentos de demarcação administrativa se iniciam de forma unilateral e que por isso ocorrem as distorções e as omissões nos relatórios antropológicos para a identificação e a demarcação das terras indígenas. Entende-se que tal procedimento existe apenas para atender aos princípios de defesa dos povos indígenas, o que, por outro lado, fere os direitos legítimos de terceiros, não índios, como tem ocorrido em diversas localidades do Estado (BORGES, 2014, p. 123). O processo demarcatório deve considerar além do procedimento técnico, o sentimento do povo que habita essas terras. O espaço a ser demarcado varia conforme os aspectos culturais e os hábitos da comunidade em questão, o que requer um criterioso estudo antropológico e um acompanhamento do processo pelos próprios indígenas.

Enfim, defender os territórios indígenas é entendido como uma forma de garantir a preservação do patrimônio ambiental desses povos. Dessa forma, a proteção de terras indígenas por meio dos procedimentos de demarcação consiste numa medida estratégica para assegurar o direito indígena e, ainda, garantir a proteção ambiental.

\section{A dialética do judiciário nas decisões sobre terras indígenas: uma análise crítica de casos em Pernambuco}

Analisam-se, então, quatro decisões judiciais no Estado de Pernambuco que versam sobre os problemas envolvendo as terras indígenas. Especificamente, essas decisões tratam dos casos de regularização, demarcação, reintegração e posse de terras indígenas que envolvem os povos indígenas e os não índios e que são fatores para o acirramento dos conflitos de terras em Pernambuco.

A primeira decisão, de número 560235/0000131-93.2012.4.05.8304, que tramita no Tribu-

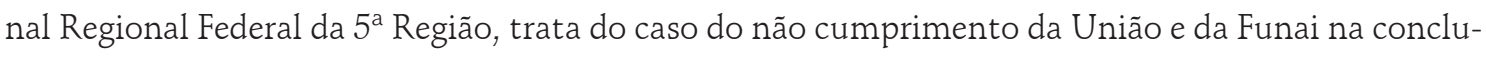
são do procedimento de demarcação das terras indígenas Truká no Município de Cabrobó, PE. Tendo já decorrido mais de 10 anos do referido caso, o magistrado de $1^{\circ}$ grau determinou que os réus, no prazo de três anos, a contar da data da sentença (25 de fevereiro de 2013), concluíssem o processo de demarcação, sob pena de fixação de multa. Destacam-se alguns trechos da decisão: 
[...] muito embora concorde que o prazo estipulado pelo magistrado de piso é bem razoável - 3 (três) anos a contar da data da sentença (25.02.2013) -, penso que, para melhor atender ao princípio da segurança jurídica e aos precedentes jurisprudenciais, é de bom alvitre acolher-se a pretensão do Ministério Público Federal, quando pleiteia o prazo de 02 (dois) anos, contados a partir do trânsito em julgado da sentença de primeira instância, nos termos do precedente do Superior Tribunal de Justiça, onde a Ministra Denise Arruda, em caso análogo ao presente, e tendo em vista o decurso de mais de 10 (dez) anos do procedimento, bem como a fase deste (que, no caso do processo julgado pelo STJ, ainda estava na fase inicial de constituição de grupo técnico) confirmou o entendimento do Juízo de que 24 (vinte e quatro meses) constituem tempo razoável para a conclusão de todo o processo demarcatório [...] (PERNAMBUCO, 2014).

É oportuno esclarecer, como bem defendeu a União Federal, que a Comunidade Indígena Truká, mesmo lutando pela concretização de tal direito, não se encontra completamente afastada de suas terras. Isso pelo fato de a Administração Pública já ter realizado, em 1996, um procedimento administrativo de demarcação de uma área de 1.650 hectares. De fato, o que se busca com a nova reivindicação é a realização de um novo procedimento demarcatório com revisão da área total da reserva indígena, por meio de novos estudos para identificação e delimitação de área.

Não se pode confirmar que o Judiciário, mesmo fixando o prazo para conclusão do procedimento administrativo da terra indígena em questão, está interferindo, indevidamente, nas ações do Poder Executivo. Conforme o que se alega, consta na decisão o seguinte pronunciamento:

É que, em razão do princípio do acesso à justiça e da inafastabilidade do controle jurisdicional para apreciar lesão ou ameaça a direito (art. $5^{\circ}, \mathrm{XXXV}, \mathrm{CF} / 88$ ), não se pode eliminar a possibilidade do Poder Judiciário de, num caso concreto, em constatando que a autoridade administrativa descumpre o dever imposto pelo legislador constituinte, e em havendo mora injustificável, determinar certo prazo, com razoabilidade, para que a Administração cumpra com seu dever, tudo com vistas a atender os princípios da duração razoável do processo e da eficiência da Administração Pública (art. 5, LXXVIII, e artigo 37, caput, da CF/88) (BRASIL, 2017b).

O juiz, na sua análise, alega que também tem como improcedentes as alegações da União e da Funai de que o Poder Judiciário estaria usurpando nas questões relacionadas à função do legislador no que concerne à fixação de multas que não estão previstas em lei.

Após a argumentação, o juiz rejeita [...] integralmente os apelos da União Federal e da Funai e dá parcial provimento aos apelos do Ministério Público Federal. Reconhece a mora dos réus e concede o prazo final de 24 meses para que a União Federal e a Funai adotem as medidas necessárias para conclusão do processo de demarcação de terras indígenas Truká em Cabrobó, PE.

A segunda decisão judicial analisada na pesquisa trata-se, ainda, das situações enfrentadas pelos indígenas em relação à demarcação de terras, que se configura como fator para geração de conflitos pela posse de terras entre índios e não índios. Trata-se de uma ação civil pública de número 0000272-78.2013.4.05.8304 ajuizada pelo Ministério Público Federal em face da Funai e da União Federal no que se refere ao não cumprimento do prazo para conclusão do processo de demarcação 
e delimitação das terras tradicionalmente ocupadas pelos índios Pankará em Carnaubeira da Penha, PE. A Funai, em suas atribuições, pronunciou-se sobre a situação, requerendo: manifestação, no prazo de 15 dias, sobre o Relatório de Identificação e Delimitação da Terra Indígena Pankará; conclusão, no prazo legal, do processo administrativo de demarcação e delimitação das terras tradicionalmente ocupadas pelos mencionados índios; e pagamento de indenização, a título de danos morais coletivos, em valor não inferior a R \$ 1.000.000,00 (um milhão de reais). Diante de tal perspectiva, é válido ressaltar que o procedimento administrativo mencionado na decisão vem sendo acompanhado desde o ano 2004 sob o processo de número 1.26.001.000006/2004-47, e teve seu início ainda em 2009, por meio da Portaria 1.014/PRES da Funai, porém até o presente não se encontra concluído por omissão desse órgão. Com isso, os conflitos de terra se tornam constantes na referida comunidade indígena, a partir da atuação de posseiros e esbulhadores não índios.

Portanto, resta, claramente, a omissão por parte do Poder Público, o que, de fato, dificulta o exercício de direitos garantidos constitucionalmente (art. 231 da CF), o que ocorre no caso dos autos. A decisão destaca:

Em situações omissivas tais, não é demais ressaltar, viável é o controle judicial do ato administrativo para que haja a restauração da ordem jurídica, que, no caso em tela, foi maculada em face da inércia e do silêncio estatal. Este tipo de atuação do Poder Judiciário frise-se, em nenhuma hipótese configura invasão da discricionariedade administrativa, eis que a liberdade que caracteriza os atos desta natureza pode desaparecer em determinadas circunstâncias, transformando-os em atos que vinculem a atuação da Administração Pública. (BRASIL, 2017a).

Nos dispositivos adotados pelo juiz, julgam-se procedentes os pedidos formulados pelos autores, nos termos decorrentes do art. 269, I, do Código de Processo Civil. É reconhecida a omissão do INCRA nas atribuições para demarcação das terras indígenas Pankará em Carnaubeira da Penha, PE. Também estabelece o prazo fixo de 60 dias, a contar do trânsito em julgado da sentença, para que o Relatório Circunstanciado de Identificação e Delimitação (RCID) das terras em questão seja devidamente concluído e analisado pelo presidente da FUNAI, nos termos do art. $2^{\circ}, \int 1^{\circ}$ ao $7^{\circ}$, do Decreto n. 1.775/96 (BRASIL, 1996).

Nessa circunstância, o juiz acolhe a preliminar de falta de interesse de agir pela União Federal de modo que extingue o processo em relação a esta. Por fim, ficou decidida a condenação da Funai ao pagamento de honorários advocatícios fixos em $\mathrm{R} \$ 3.000,00$, devidamente atualizados, com fundamento no art. 27, $\iint 1^{\circ}$ e $3^{\circ}$, II, do Decreto-Lei n. 3.365 c/c art. 20, $\$ 4^{\circ}$, do Código de Processo Civil.

A terceira decisão analisada trata de um Recurso Especial n. 646.933-PE (2003/02301693), que tramita no Tribunal Regional Federal da $5^{\text {a }}$ Região, relativo a ações de reintegração de posse em face do grupo indígena Xucuru, tendo por objeto a posse de imóvel rural denominado Fazenda Caípe, com uma área de aproximadamente 300 hectares localizada no Município de Pesqueira, PE. 
Interposto recurso de apelação, o egrégio Tribunal Regional Federal da $5^{\text {a }}$ Região negou provimento, reiterando os seguintes argumentos:

1) Não há que se falar em nulidade da sentença, por não ter sido deferida produção de prova pericial e testemunhal, se os elementos apresentados nos autos foram suficientes para firmar o convencimento do juízo acerca do exercício da posse sobre o Sítio citado na peça exordial pelos autores e seus ancestrais, desde 1895, pelo menos; 2) o decisório atacado não precisaria se pronunciar especificamente sobre a proteção possessória solicitada pelo grupo indígena que reinvidica área, porque, com o reconhecimento judicial do direito dos autores à reintegração, restou prejudicado o pleito atinente à dita proteção, decorrente da natureza dúplice das ações possessórias; 3) considerando que a Constituição Federal de 1988 atribui à União a titularidade do domínio sobre as terras tradicionalmente ocupadas por indígenas e a dita entidade política efetuou a demarcação do imóvel em questão para fins de enquadramento na proteção constitucional, impõe-se a sua presença no pólo passivo desta demanda; 4) conforme a doutrina pátria, ao interpretar os dispositivos constitucionais que tratam da matéria apenas fazem jus à posse dos imóveis rurais os silvícolas que as ocupavam quando da promulgação da Constituição de 1934, o que ocorre no caso concreto, onde a propriedade do bem (ou, pelo menos, a sua posse) pertence aos antecessores dos autores desde o final do século XIX. (BRASIL, 2017b).

Diante da decisão, a Funai alega, preliminarmente, cerceamento de defesa e nulidade, em face do julgamento antecipado da lide, sem a realização de perícia técnica, requerida pela recorrente, de natureza administrativo-antropológica e de prova testemunhal, para o fim de comprovar a tradicionalidade da ocupação indígena na região. A União, por sua vez, reitera que o Tribunal, ao considerar que o imóvel não poderia ser considerado terra tradicionalmente ocupada pelos índios, necessariamente, deveria ter recorrido que a União era parte ilegítima na presente ação, por se tratar de terreno não pertencente ao seu domínio. Restou comprovado que a União, titular do domínio sobre terras tradicionalmente ocupadas pelos indígenas (art. 20, IX, da Constituição de 1988), procedeu a demarcação do imóvel em questão, objetivando o seu enquadramento na proteção constitucional. Portanto, independentemente da procedência das ações de reintegração de posse, manifestou a União interesse direto no feito, não podendo se falar em ilegitimidade da parte.

Na decisão final, os ministros da quarta turma do Superior Tribunal de Justiça justificaram não conhecer os recursos especiais que tratam da reintegração de posse do imóvel rural, objeto de litígio, em face do grupo indígena Xucuru. Com isso, deve-se anular a decisão que concedeu a liminar, sem atentar para a regra insculpida nesse dispositivo legal.

A quarta decisão judicial trata de um agravo de instrumento de número 9182.5996/437200800001423, que tramita no Tribunal de Justiça de Pernambuco e trata de pedidos para fins de reintegrar à autora (Maria das Graças Oliveira), ora agravada na posse do imóvel objeto de litígio localizado em Petrolândia, PE, que seria de propriedade de seu falecido esposo bem assim que antecipou os efeitos da tutela para, independente do trânsito em julgado da sentença, determinar a imediata reintegração de posse da demandante, assinalando ao réu, indígena Kambiwá, substituído pela Funai, o prazo de 45 dias para desocupação do imóvel, sob o pagamento de multa. Em relação à 
legitimidade da Funai, a sua intervenção na situação abordada na sentença ocorreu na qualidade de substituto processual do réu, índio Kambiwá, com fulcro na Lei n. 5.371/67, que disciplina a representação da fundação nos requisitos de assistência jurídica aos índios.

Pode-se analisar que o dispositivo da decisão possui caráter nitidamente executivo, conferindo à sentença aptidão intrínseca para levar à efetiva satisfação do credor, independente de execução. Nela fica alegado que o indígena representado processualmente ocupou o imóvel (objeto de litígio) em apreço por mais de cinco anos, nele tendo procedida à implantação de benfeitorias e culturas agrícolas ou plantação, razão pela qual, defende, tem direito à retenção como possuidor de boa-fé. Assim, a decisão final dos juízes integrantes da $7^{\text {a }}$ Câmara Cível do Tribunal de Justiça do Estado de Pernambuco foi negar provimento ao presente recurso.

Diante das análises e interpretações das presentes decisões, é justo ressaltar que o Poder Judiciário no Estado de Pernambuco tem se mostrado pouco hábil para lidar com os casos que envolvem litígios de terras indígenas. Um quantitativo muito pequeno de decisões se propõe a buscar uma real solução para os conflitos, e, por isso, muitas de suas decisões são socialmente desconfirmadas. Ressalte-se que as decisões judiciais sobre demarcação de terras são constitutivas, pois implicam uma mudança da situação jurídica da comunidade, com fortes implicações para suas realidades sociais.

\section{Considerações finais: a realidade do Judiciário pernambucano nas tomadas de decisões envolvendo terras indígenas - uma real necessidade no cumprimento das exigências constitucionais}

Nesta pesquisa, observou-se que as demandas relacionadas às terras indígenas que são levadas a âmbito judiciário são, em vias de regras, interpretadas, na grande parte dos casos, como uma afronta ao direito de propriedade. A Constituição Federal de 1988 revela um considerável avanço em direção à conquista do direito à terra pelos povos indígenas, porém o que se verificou foi um Judiciário marcado pelo forte teor civilista, seja por meio das interpretações do direito, seja na análise processual. Mesmo as decisões que vêm ao encontro das aspirações dos povos indígenas dificilmente conseguem encontrar outro percurso para esse viés. Nessa perspectiva, as reivindicações dos povos indígenas em Pernambuco, especialmente quanto à regularização nos procedimentos demarcatórios de suas terras, não encontram no Judiciário um campo favorável para a concretização dos princípios constitucionais.

Torna-se claro que a interpretação dos princípios constitucionais aplicáveis ao indígena nas decisões judiciais ainda é bastante precária por parte do Judiciário Pernambucano. Limita-se, de certa forma, a transcrever o dispositivo que trata da propriedade privada, porém, não se detém a uma análise criteriosa para o dispositivo que estabelece acerca de sua função social. Justifica-se, dessa forma, a insuficiência de aprofundamento e análise acerca das questões indígenas por parte dos juízes e magistrados. A causa indígena não tem sido, muitas vezes, pauta de discussão por parte dos 
representantes desse setor, o que deixa os povos indígenas à mercê dos conflitos e da inaplicabilidade das políticas públicas específicas a esse grupo étnico.

Portanto, o Judiciário pautado pelos princípios constitucionais, permeado de discussão aberta e ao mesmo tempo coerente, trará resultados significativos na concretização de direitos dos povos indígenas no Estado de Pernambuco. Nos casos de demarcação de terras indígenas em Pernambuco fica evidente a relação frequente entre o plano político e o plano jurídico-administrativo nos processos que envolvem a tomada de decisão sobre direitos indígenas à terra.

\section{Referências}

ANTUNES, Paulo de Bessa. Ação Civil Pública, Meio Ambiente e Terras Indígenas. Rio de Janeiro: Lúmen Júris, 1998.

BARBOSA, Marco Antonio. Direito Antropológico e Terras Indígenas do Brasil. São Paulo: Plêiade; Fapesp, 2001.

BORGES, Antonino Moura. Terras Indigenas e seus conflitos atuais. Campo Grande: Contemplar, 2014.

BRASIL. Constituição. República Federativa do Brasil de 1988. Brasília, DF: Senado Federal, 05 out. 1988.

BRASIL. Decreto n. 1.775, de 08 de janeiro de 1996. Dispõe sobre o procedimento administrativo de demarcação das terras indígenas e dá outras providências. Disponível em: <http://www.planalto. gov.br/ccivil_03/decreto/D1775.htm >. Acesso em: 06 jan. 2014.

BRASIL. Lei n. 6.001, de 19 de dezembro de 1973. Dispõe sobre o Estatuto do Índio. Diário Oficial da União, 21 dez. 1973. Disponível em: <http://www.planalto.gov.br/ccivil_03/leis/16001.htm>. Acesso em: 05 jan. 2014.

BRASIL. Seção Judiciária de Pernambuco - 20a Vara Federal. Processo no 0000272-78.2013.4.05.8304. Disponível em: < http://www.mpf.mp.br/atuacao-tematica/ccr6/dados-da-atuacao/acoes-coordenadas/dia-do-indio/docs-terras-indigenas/acp-0000272-78-2013-4-05-8304-etnia-pankara-decisao>. Acesso em: 08 maio 2017a.

BRASIL. Tribunal Regional Federal 5a Região. Apelação Cível no AC 178199 PE 9905351329. Disponível em: <https://trf-5.jusbrasil.com.br/jurisprudencia/163515/apelacao-civel-ac-178199-pe-990535132-9>. Acesso em: 08 maio 2017b.

CONSELHO ECONÔMICO E SOCIAL DAS NAÇÕES UNIDAS. Comissão Econômica para a América Latina e o Caribe. 2006.

FALCÃO, Ismael Marinho. As terras indígenas. In: FALCÃO, Ismael Marinho. Direito agrário brasileiro: doutrina, jurisprudência, legislação e prática. Bauru: Edipro, 1995.

FUNAI. As Terras Indigenas. 2005. Disponível em: <http://www.funai.gov.br/index.php/indios-no-brasil/terras-indigenas>. Acesso em: 30 dez. 2014. 
GRABNER, Maria Luiza. Terra indígena: demarcação de terra indígena. Dicionário de direitos Humanos - DDH. Dicionário tipo enciclopédico, 2009. Disponível em: <http://www.esmpu.gov.br/ dicionario/tiki_index.php? page =Terra + ind\%C3\%ADgena\%3A+demarca\%C3\%A7\%C3\%A3o+de+terra+ind $\%$ C3\%ADgena $>$. Acesso em: 30 dez. 2014.

MARIÁTEGUI, José Carlos. El problema de las razas en la América Latina. In: QUIJANO, A. (Selección, prólogo y notas introductorias) José Carlos Mariátegui: textos básicos. Lima: Fondo de Cultura Económica, 1991.

MARIÁTEGUI, José Carlos. Sete ensaios de interpretação da realidade peruana. São Paulo: Expressão Popular, 2010.

MONTANARI JUNIOR, Isaias. Terra indígena e a Constituição Federal: pressupostos constitucionais para a caracterização das terras indígenas. Disponível em: <http://conpedi.org/manaus////arquivos/anais/manaus/estado_dir_povos_isaias_montanari_jr.pdf>. Acesso em: 28 dez. 2014.

PERNAMBUCO. Marco dos Povos Indígenas em Pernambuco. Disponível em: < http://www.sara. pe.gov.br>. Acesso em: $11 \mathrm{dez} .2014$.

QUIJANO, Aníbal. Colonialidade do poder, Eurocentrismo e América Latina. Buenos Aires: Consejo Latinoamericano de Ciencias Sociales, 2005. Disponível: <http://bibliotecavirtual.clacso.org.ar/ clacso/sur-sur/20100624103322/12_Quijano.pdf>. Acesso em: 17 abr. 2017.

SANTILLI, Márcio. Os direitos indígenas na Constituição brasileira. In: CENTRO ECUMÊNICO DE DOCUMENTAÇÃO E INFORMAÇÃO. Povos Indígenas no Brasil 1987/88/89/90. São Paulo: CEDI, 1991. p. 11-14.

SOUZA LIMA, Antônio Carlos; BARROSO-HOFFMANN, Maria (Org.). Além da tutela: bases para uma nova política indigenista III. Rio de Janeiro: Contracapa; LACED, 2002.

VEIGA RIOS, Aurélio. Terras indígenas no Brasil: definição, reconhecimento e novas formas de aquisição. In: SOUZA LIMA, Antonio Carlos; BARROSO-HOFFMANN, Maria (Org.). Além da tutela: bases para uma nova política indigenista III. Rio de Janeiro: Contra Capa/LACED, 2002. p. 65-66.

Data da submissão: 31 de agosto de 2017 Avaliado em: 25 de março de 2017 (AVALIADOR A) Avaliado em: 17 de setembro de 2017 (AVALIADOR B) Aceito em: 04 de agosto de 2017 
